\title{
Unos retazos de luz para una crisis interminable
}

\author{
Glimmering Lights Amid Endless Crisis
}

Julio Montes Santiago ${ }^{1,2}$

${ }^{1}$ Servicio de Medicina Interna. Complejo Hospitalario Universitario de Vigo. SERGAS. Vigo

2Presidente de la SOGAMI

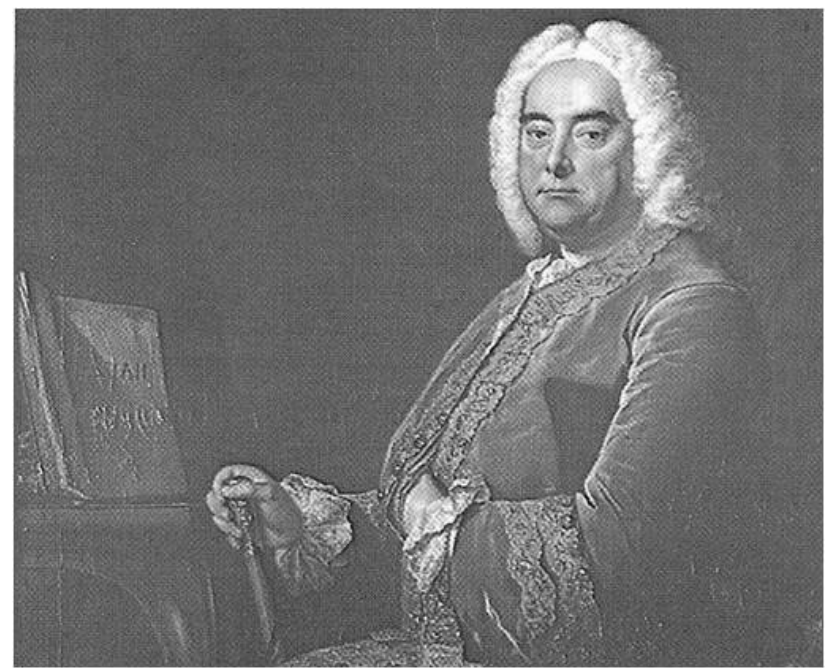

Figura 1. Georg Friedrich Händel

Hace 272 años, en 1741, George Frederic Haendel (Figura 1) se encontraba exhausto. Repetidos ataques de gota y varios ictus, de los cuales se había recuperado casi milagrosamente, habían mermado, sin embargo, su ánimo y su salud. Una sensación de lasitud, de agotamiento, de que la inspiración se volvía irremediablemente esquiva, le atenazaba. Además ahora, como si fuera una burla del destino, un oscuro poeta admirador -Jennens- le mandaba una obra confiando que la musicara. Desfallecía. La muerte era cada vez más un agradable pensamiento. Casi sin darse cuenta abrió el sobre remitido por su admirador. Era para un oratorio. Sus últimos oratorios habían fracasado. Este llevaba por título El Mesías. Comenzó a leer: Consolaos... Así comenzaba. Así habló el Señor... De repente algo cambió en su interior y en su alma se desbordó la música. Ella, tan huidiza, ahora pareció colmar todos los repliegues y comenzó a escribir, febril, incansable -Aleluya, Aleluya, Aleluya...-, hasta completar la obra en solo tres semanas. Quiso estrenarla en Dublín, la ciudad que le había acogido con cariño. Y allí estrenó El Mesías. Fue un acontecimiento. Al día siguiente volvió a representarse. Más de 700 personas abarrotaban hasta los topes el humilde teatro. Lo nunca visto. Y el silencio era sepulcral. En los 27 Aleluyas finales -King of Kings, and Lord of Lords, for ever and ever...-
Haendel agradecía a Dios la inspiración, y a aquellas gentes su confianza. Con gratitud, la recaudación de todo aquello fue para los miserables, los pobres, los enfermos del hospital Mercier... Unos días después se estrenó también en Londres, en presencia de la familia real. Desde entonces, El Mesías siempre se escucha allí de pie. Los Aleluyas quedan flotando y la gloria de Haendel permanece imperecedera'.

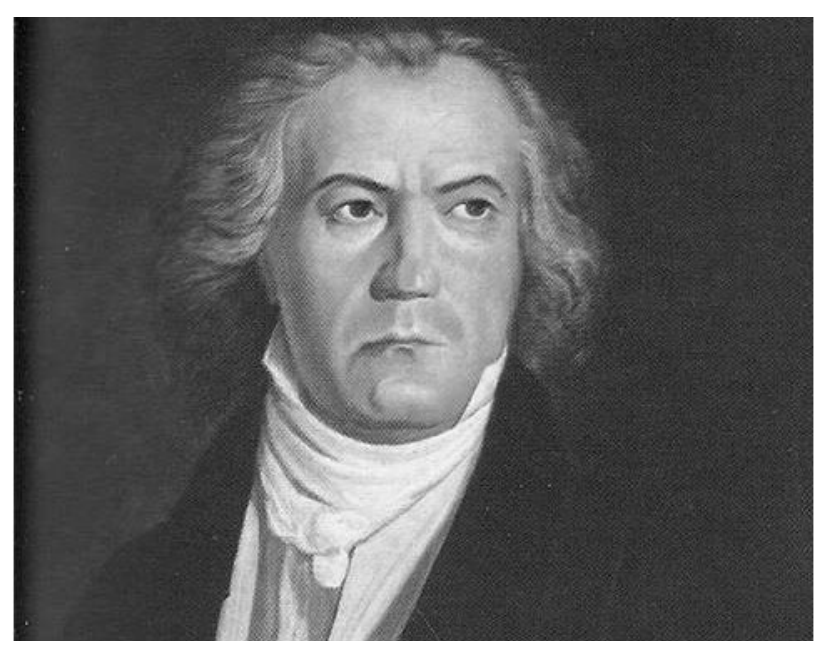

Figura 2. Ludwig van Beethoven

Hace 190 años, en 1823, Beethoven (Figura 2) también se encontraba desesperado. Sordo desde hace incontables años, considerado una reliquia antidiluviana por muchos, huraño, mal vestido, misántropo, abandonado de su higiene personal, con múltiples achaques.... Parece que el destino, del que había dicho con frecuencia que era preciso agarrar por el cuello para evitar que nos aplaste, se tomaba ahora cumplida revancha. La depresión, el olvido o el suicidio parecían la salida lógica para aquel hombre. Sin embargo, todavía en su interior quedaban rescoldos que pudieran inflamarse. Olvidando todos sus males buscó inspiración en otra obra emocionante de su compatriota Schiller, la Oda a la Alegría. "Ven, canta, sueña cantando, vive soñando el nuevo sol, en que los hombres volverán a ser hermanos...." Y se aplicó a hacerla clamar por los coros y la música. La noche del 7 de mayo de 1824 la humanidad estupefacta contempló el milagro. La contralto Caroline Unger 
volvió delicadamente al sordo maestro de cara al público. Beethoven, que dirigía la orquesta, estaba incapacitado para apreciar la sublime música. Pero el Teatro Imperial de Viena estallaba en atronadores aplausos. Acababa de producirse uno de los momentos estelares de la humanidad. Era la primera audición de la Novena Sinfonía².

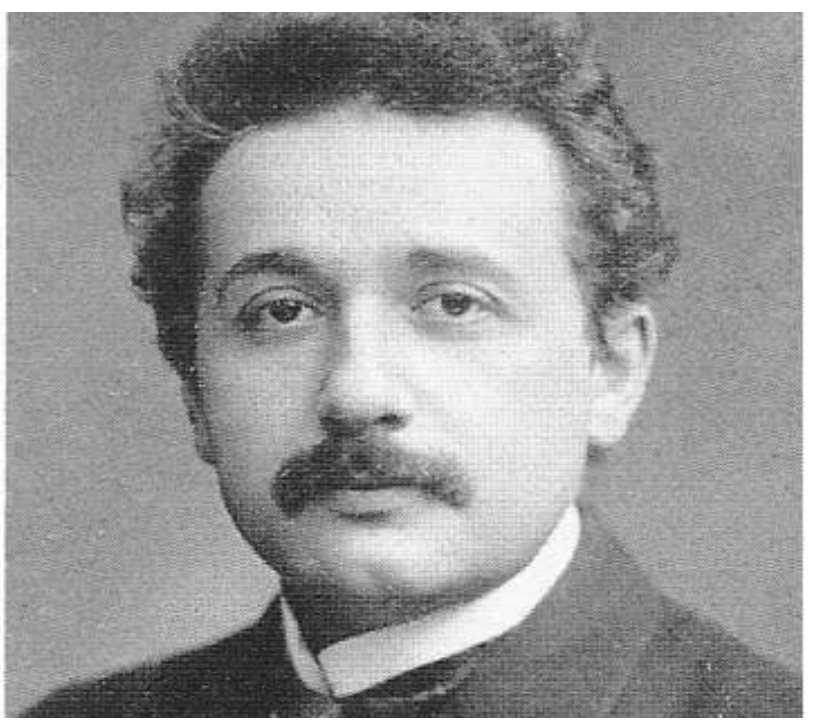

Figura 3. Albert Einstein

Hace 100 años, en 1913, Einstein (Figura 3) había llegado a su límite personal e intelectual y se internaba en su particular crisis. Estaba embarcado en intentar ampliar su Teoría de la Relatividad. Trabajaba en una hipótesis -Entwurf, el Esbozo o Diseño-, pero había llegado a un sitio sin salida; las ecuaciones planteadas no hallaban la solución. Además, su relación con su esposa Mileva se había deteriorado hasta un punto intolerable. De hecho, terminaría en divorcio pocos años más tarde. Sus hijos en Zurich se preguntaban frecuentemente por qué el padre ausente en Berlín no acudía a visitarlos. Poco a poco, con mucho esfuerzo, comprendió que debía abandonar el Esbozo y explorar otras alternativas. Por fin, al final de 1915 encontraba las soluciones matemáticas para la Teoría de la Relatividad General. Aunque para ello debió recibir la ayuda del famoso matemático David Gilbert. El mundo asistía estupefacto al nacimiento de tal revolución científica. Cuatro años después un eclipse solar confirmaba sus predicciones. Einstein era catapultado a la inmortalidad ${ }^{3}$.

Hace 84 años, en 1929, el mundo occidental parecía haber terminado. El crack de la bolsa de Nueva York se había extendido rápidamente por todo el mundo civilizado. Miseria, suicidio, depresión, agitaciones, incertidumbre... También el mundo del arte se encontraba perplejo tras el fin abrupto de la Belle Epoque y los felices 20. En estado de shock, todo el mundo se preguntaba que iba a ser de la creación artística. El talento parecía haber sido asesinado. Sin embargo, esta humanidad logró bucear en sí misma y se regaló de nuevo un renacimiento increíble y multicultural: Klee, Dalí, Mondrian, John Cage, Miró, Man Ray, Kandinsky, Siqueiros, Rivera, Frida Kahlo... Otra vez la luz aparecía en el final del tortuoso camino ${ }^{4}$.

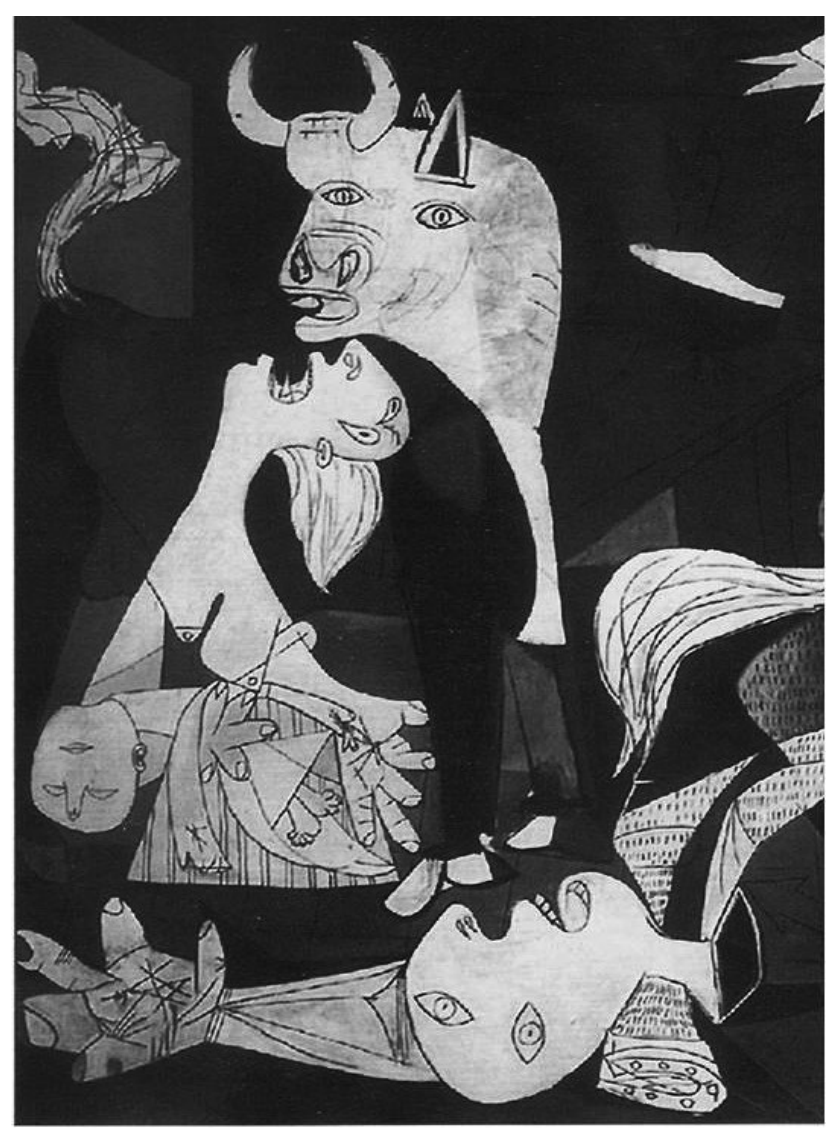

Figura 4. Detalle del Guernica. Pablo Picasso 
Hace 75 años, en 1937, la aviación alemana consumaba el bombardeo de una ciudad vasca. Ante este horror, Picasso se encerraba durante meses en un ático de la Rue des Grands Agustins, en París. Allí, superando sus crisis personales, alumbraba la creación más paradigmática del siglo XX: el Guernica ${ }^{5}$ (Figura 4). Al principio incomprendida por algunos, que la tachaban de poco comprometida, o criticada por otros, que la hallaban críptica, dicha obra se acabaría erigiendo en el alegato más definitivo contra todas las formas de violencia y contra todos los horrores de la guerra. Aunque lo peor aún estaba por venir y poco tiempo después comenzaría la $\|^{a}$ Guerra Mundial. Pero, tras esta purificación, otra vez el arte renacería de las cenizas. En Norteamérica (p.ej.) el surrealismo abstracto surgiría con incontenible empuje, con Jackson Pollock o Willem De Kooning como abanderados, y Haring, Basquiat o Andy Warhol y el Pop Art como discípulos aventajados.

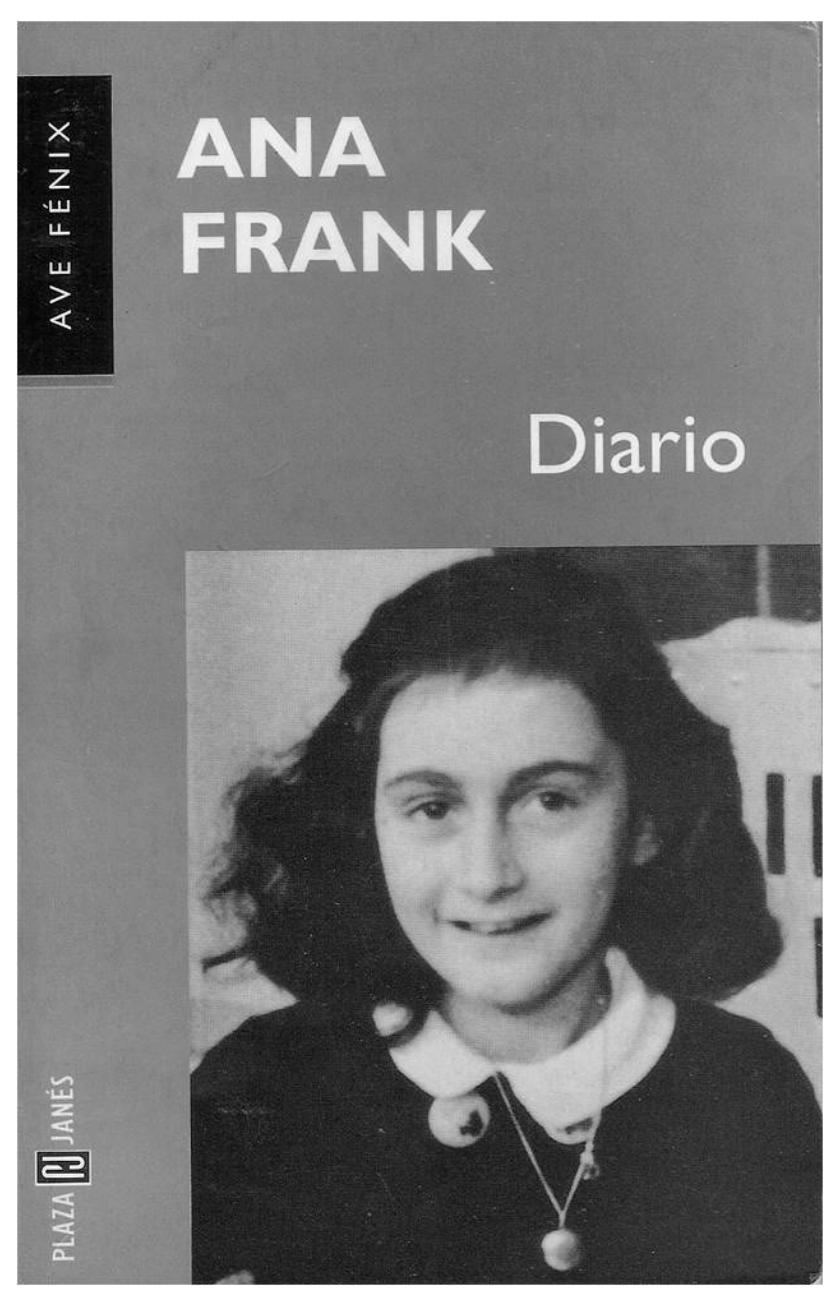

Figura 5 El diario de Ana Frank

Hace 58 años, en 1945, uno de los momentos más críticos de la humanidad, moría de tifus en un campo de concentración una muchacha de apenas 16 años. Se llamaba Ana Frank. Moría la persona pero nacía una esperanza. Su Diario sigue manteniéndola enhiesta (Figura 5). Nelson Mandela, desde su prisión sudafricana en el Apartheid, afirmará con convicción: "Para algunos de los que estuvimos [prisioneros] en Robben, la lectura del Diario de Ana Frank supuso un gran aliento". Y Ana había dejado escrito en él, apenas unos meses antes de ser deportada al lugar donde morirá: "No pienso ya en la miseria sino en la belleza que sobrevivirá[...]. El que es feliz puede hacer felices a los demás. El que no pierde el valor y la confianza no se moriría nunca de pena ${ }^{56}$

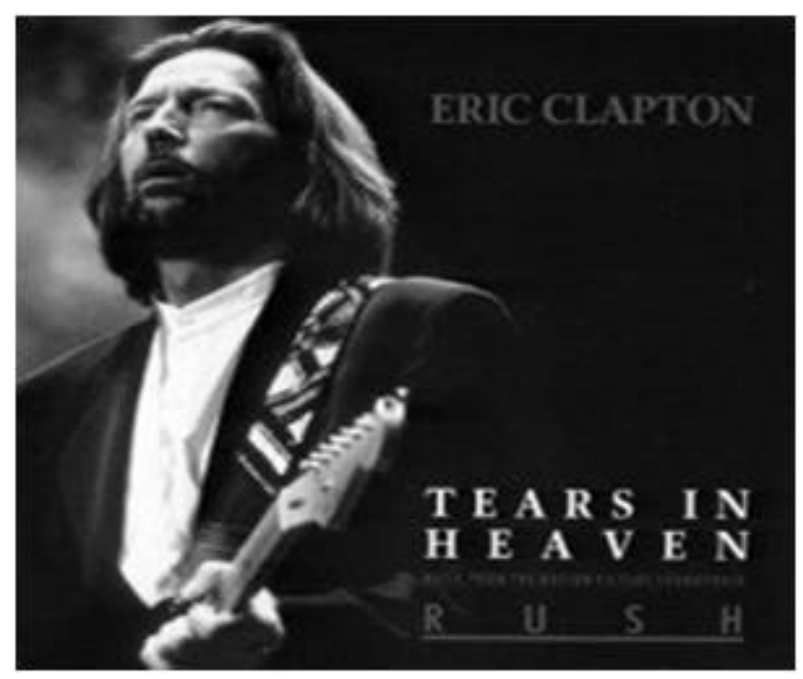

Figura 6. Tears in Heaven. Eric Clapton

Hace 12 años, en 1991, Eric Clapton, el talentoso músico y guitarrista inglés, atravesaba también su profunda crisis personal. Su hijo Conor, de 4 años, moría en un desgraciado accidente, al caer por la ventana de un rascacielos de Nueva York. Sumido en la desesperación, recogió su dolor, lo incubó en sus entrañas y lo engendró hecho música en la conmovedora Tears in Heaven (Lágrimas en el cielo) (Figura 6). Considerada por muchos una de sus mejores canciones, aún hoy siguen resonando íntimamente y estremeciendo las preguntas al hijo ya irremediablemente arrebatado: Would you know my name if I saw you in heaven? ¿Recordarás mi nombre, cuando te vea en el cielo?... And I know there'll be no more tears in heaven... Y sé que no habrá más lágrimas en el cielo?.

Hace 9 meses, en mayo de 2012, tras una larga noche de insomnio, velando el inquieto descanso de mi madre enferma -que moriría sólo una semana después-escribí estas líneas, para hacerme presente en el futuro tales momentos, cuando el camino de la vida se empinara: "El sufrimiento y la crisis pueden ser como un vendaval que deje todo desnudo, pero cuando se sobrevive, ocurre como las lapas adheri- 
das a las rocas, son ya la misma roca y han adquirido su fuerza para afrontar temporales futuros".

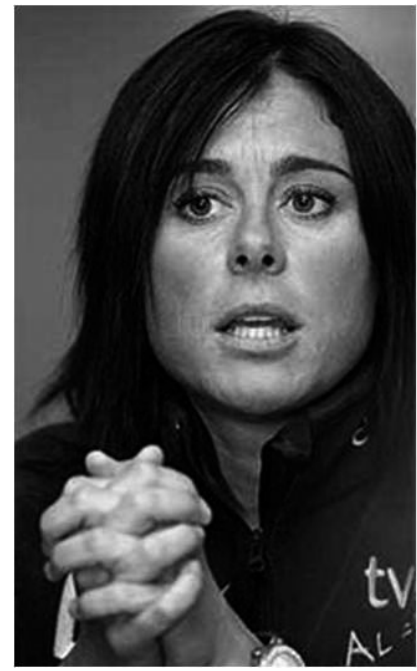

EDURNE PASABÁN ANGÉLICA DEL CARPIO

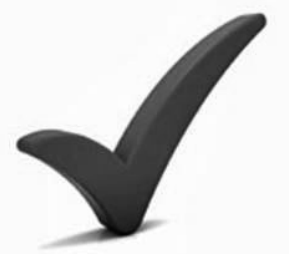

OBJETIVO CONFIANZA

La via para reconocer y superar nuestros auténticos retos

conecto

Figura 7. Objetivo confianza. Edurne Pasabán

Hace 9 semanas, en diciembre de 2012, Edurne Pasabán, la conocida alpinista vasca y primera mujer en coronar los 14 ochomiles sin oxígeno, acaba de publicar un libro -escrito en colaboración con Angélica del Carpio- titulado Objetivo confianza (Ed. Conecta). (Figura 7). Y es significativo porque lo escribe reflexionando sobre una experiencia fallida: la expedición de 2011 al Everest. Ella misma reconoce que versa sobre "una historia de aprendizaje que trata de sacar la parte positiva de los errores"вa. Podría haber elegido cualquiera de sus grandes triunfos, pero eligió esta expedición que acabó en fracaso rotundo: el tiempo infernal, el cansancio, el hastío, quizás la mala planificación, con el final de la desastrosa bronca mediática con Juanito Oiarzábal, sobre los pormenores de un rescate... Tales circunstancias no permitieron el éxito de dicha expedición, pero la lección final queda clara: quien no se arriesga nada gana. Pues bien, en las entrevistas de promoción de su obra llega a afirmar: "El libro no ofrece una receta mágica... Me encantaría dar un mensaje alentador, pero a veces hasta a mí me falta la confianza..." "8b.

Amigos, hoy os escribo esto porque yo también necesito una mano, -"with a little help from my friends", "con una leve ayuda de mis amigos"-, como muchos hemos tarareado con la conocida canción de los Beatles. Me dirijo a vosotros pero fundamentalmente también a mí mismo, para no desfallecer, para seguir en la brecha cuando todo parezca baldío, para -como Beethoven- si no es posible encontrar la alegría en esta tierra, seguirla buscando más allá de las estrellas... Desde hace tiempo estoy convencido de que es imposible superar solos las crisis; nos necesitamos unos a otros. Estas reflexiones son de agradecimiento porque cuando ya no

veo la ruta, siempre hay algunos de vosotros que, como el camarada alpinista en la cordada o el compañero ciclista que se acerca con el agua, seguís animándome y mostrando el camino.

Gracias a vuestro entusiasmo siguen celebrándose las reuniones del Grupo GRIVA y publicando sus ponencias; el Grupo de Alcoholismo completada ya su base de datos de la encefalopatía de Wernicke; el Grupo de Infecciosas sigue celebrando sus Seminarios; acaba de celebrarse la Reunión del grupo Nacional y tiene nuevos proyectos el Grupo de Autoinmunes; el Grupo de Insuficiencia Cardiaca organiza sesiones interdisciplinarias con Cardiología; se establecen estrategias de colaboración para elaborar protocolos en procesos pluripatológicos con disciplinas como Cardiología, Neumología, Atención Primaria, Enfermería...Para el año que viene están aseguradas ya las reuniones de Internistas Noveis, organizadas por el Grupo de Formación. Continúan celebrándose las Sesiones interhospitalarias. Tengo ya el ofrecimiento para reanudar las reuniones formativas en los Hospitales Comarcales. Galicia Clinica, a pesar de las dificultades, continúa con su singladura, etc. $Y$ tantas otras cosas que seguramente por mi mala cabeza no puedo recordar ahora...

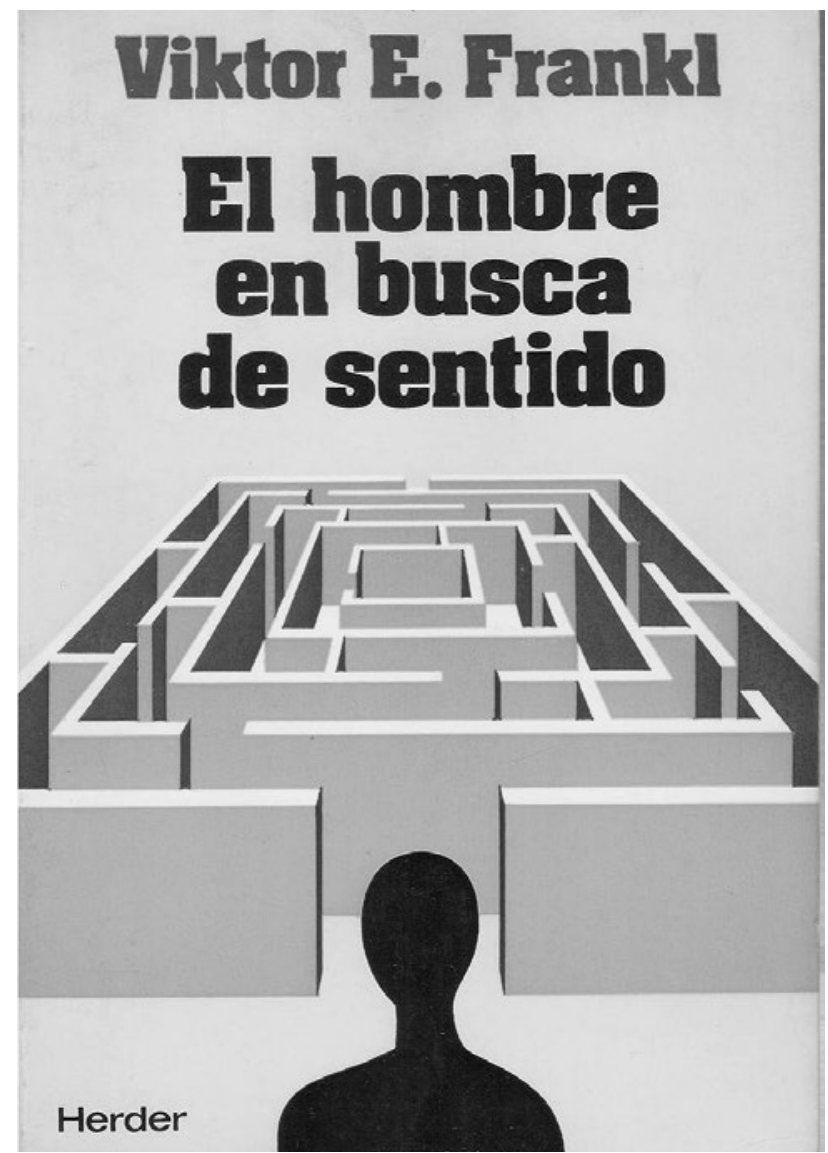

Figura 8. El hombre en busca de sentido. Victor Frankl 
Arrecian los tiempos pero todos ellos nos hacen mirar con esperanza al futuro. Esta crisis parece interminable pero no es, ni mucho menos, la peor, ni será la última. El siglo XXI ha comenzado con el horror del 11 de septiembre, la tragedia ecológica y humana del Prestige y la Guerra de Irak, pero también se inició con el heroísmo de policías y bomberos que perecieron tratando de ayudar a sus semejantes; con ese ejemplo extraordinario que constituyó el voluntariado de gentes venidas de todas partes y que dibujaron una marea blanca de solidaridad en las playas de Galicia; con el rechazo unánime de la comunidad internacional a la Guerra de Irak, etc ${ }^{9}$.

El siglo XXI está intentando aprender y rehacerse de los errores del XX. Como sostiene el psicólogo experimental y científico evolucionista de Harvard, Steven Pinker, y Eduard Punset repite incansablemente ${ }^{10}$, este tiempo nuestro es el de menor violencia en la historia de la Humanidad. Aunque a veces nos parezca que esta ha aprendido muy poco de su reciente historia. Por eso, independientemente de las creencias filosóficas o religiosas de cada cual, esta es todavía una época de esperanzas. Y en las presentes fechas, son tiempos de reencuentros, de veladas entrañables, de sueños de futuros mejores...

Por ello quiero terminar recordando unas palabras que siempre fueron estimulantes para mí. Y quizá pueden ayudar a alguno. Fueron pronunciadas tras superar angustiosas crisis personales y contemplar espantosas catástrofes colectivas. Victor Frankl, psiquiatra austriaco de origen judío, discípulo de Freud y profesor de Psiquiatría en las Universidades de Viena y San Diego relata en la obra El hombre en busca de sentido, (Figura 8), sus experiencias como sobreviviente de un campo nazi de exterminio. El libro acaba con la siguiente reflexión sobre la condición humana: "Nuestra generación es realista, pues hemos llegado a saber lo que es realmente el hombre. Después de todo, el hombre es ese ser que ha inventado las cámaras de gas de Auschwitz, pero también es el ser que ha entrado en esas cámaras con la cabeza erguida y el Padrenuestro o el Shemá Israel en sus labios"11.

\section{Bibliografía}

1. Zweig S. La resurrección de Georg Friedich Haendel. En: Momentos estelares de la humanidad (Trad. B. Vias Mahou). Acantilado: Barcelona, 2002. pp. 95-120.

2. Montes Santiago J. El coleccionista de cráneos célebres. Maturana: Barcelona, 2007, p. 102

3. Sánchez Ron JM. Albert Einstein: su vida y su obra. Monografías de la Real Academia de Ciencias de Zaragoza, 2005; 27: 11-24.

4. Cancho M. El “Guernica” cumple 75 años. Europa 2012; 110: 13-14.

5. Royuela S. El Guernica. Picasso y los horrores de la guerrra. Memoria de la Historia 2012; 46: 71-80.

6. Frank, Ana. Diario. $7^{a}$ ed. (Trad. DJ. Puls). Plaza \& Janés: Barcelona, 1993. (Publicación original, 1983).

7. Tears in heaven (by Eric Clapton). Disponible en: http://en.wikipedia.org/wiki/Tears_ in_Heaven (acceso 02/12/2012).

8. a) Agencia EFE. Pasabán hace un repaso a sus errores en el libro "Objetivo confianza". Disponible_en:_http://www.noticiasdenavarra.com/2012/12/06/deportes/montanismo/pasaban-hace-un-repaso-a-sus-errores-en-el-libro-objetivo-confianza. b) Mengual M. Entrevista a Edurne Pasabán. El Mundo, 02/12/2012. Disponible en www.elmundo.es (acceso 02/12/2012).

9. Montes Santiago J. Tabaco y medios de comunicación. Una atracción fatal. Copiart: Vigo, 2003.

10. Santamaría G. Steven Pinker. La evolución pacifista. Redes para la Ciencia 2012; 33: $42-45$.

11. FrankI VE. El hombre en busca de sentido. (Trad: Diorki). $5^{\mathrm{a}}$ ed. Herder: Barcelona, 1984. (Publicación original, 1962). 